Relations industrielles

Industrial Relations

\title{
Liste des appréciateurs 1999 1999 List of Referees
}

Volume 54, numéro 4, 1999

URI : https://id.erudit.org/iderudit/051287ar

DOI : https://doi.org/10.7202/051287ar

Aller au sommaire du numéro

Éditeur(s)

Département des relations industrielles de l'Université Laval

ISSN

0034-379X (imprimé)

1703-8138 (numérique)

Découvrir la revue

Citer ce document

(1999). Liste des appréciateurs 1999. Relations industrielles / Industrial Relations, 54(4), 846-847. https://doi.org/10.7202/051287ar

Tous droits réservés (C) Département des relations industrielles de l'Université Laval, 1999
Ce document est protégé par la loi sur le droit d'auteur. L'utilisation des services d'Érudit (y compris la reproduction) est assujettie à sa politique d'utilisation que vous pouvez consulter en ligne.

https://apropos.erudit.org/fr/usagers/politique-dutilisation/ 


\section{Liste des appréciateurs 1999}

\section{List of Referees}

Les membres du Comité de direction remercient les personnes suivantes pour leur contribution utile à la Revue en évaluant des manuscrits durant la dernière année se terminant le 10 novembre 1999.

The members of the Executive Committee gratefully acknowledge the contribution of the following individuals who assessed manuscripts for the Journal during the year ending November $10^{\text {th }}, 1999$.

$\begin{array}{ll}\text { ADELL, Bernard } & \text { CHICHA, Marie-Thérèse } \\ \text { Queen's University } & \text { Université de Montréal } \\ \text { BAUMONT, Phil } & \text { COUSINEAU, Jean-Michel } \\ \text { University of Glasgow } & \text { Université de Montréal } \\ \text { BÉLANGER, Jacques } & \text { FORREST, Anne } \\ \text { Université Laval } & \text { University of Windsor } \\ \text { BERGERON, Jean-Louis } & \text { GUÉRIN, Gilles } \\ \text { Université de Sherbrooke } & \text { Université de Montréal } \\ \text { BICH, Marie-France } & \text { HARRISON, Denis } \\ \text { Université de Montréal } & \text { Université du Québec à Hull } \\ \text { BLOUIN, Rodrigue } & \text { KUMAR, Pradeep } \\ \text { Université Laval } & \text { Queen's University } \\ \text { BOIVIN, Jean } & \text { LAFLAMME, Roch } \\ \text { Université Laval } & \text { Université Laval } \\ \text { BOURQUE, Reynald } & \text { LALLEMANT, Michel } \\ \text { Université de Montréal } & \text { Université de Rouen } \\ \text { BROSSARD, Michel } & \text { LAPOINTE, Paul-André } \\ \text { Université de Montréal } & \text { Université Laval } \\ \text { CARTER, Donald D. } & \text { MAGNAN, Michel } \\ \text { Queen's University } & \text { École des Hautes Études Commer- } \\ \text { CHAISON, Gary N. } & \text { ciales } \\ \text { Clark University } & \text { MAZEROLLE, Maurice } \\ \text { CHAREST, Jean } & \text { Wilfrid Laurier University } \\ \text { Université de Montréal } & \text { MELTZ, Noah } \\ & \text { University of Toronto }\end{array}$


MORIN, Fernand

Université Laval

PAQUET, Renaud

Université du Québec à Hull

PÉRUSSE, Michel

Université Laval

PETIT, André

Université de Sherbrooke

PONAK, Allen

University of Calgary

RONDEAU, Claude

Université Laval

ROSE, Joseph B.

McMaster University

THÉRIAULT, Roland

Société Conseil Mercer
THOMPSON, Mark

University of British Columbia

TRUDEAU, Gilles

Université de Montréal

VERGE, Pierre

Université Laval

VERMA, Anil

University of Toronto

VINET, Alain

Université Laval

Voos, Paula B.

Rutgers University

WILS, Thierry

Université Laval 